\title{
EVALUATION OF THE BRAIN PERFUSION OF THE PATIENTS WITH BRAIN METASTASES
}

\author{
Peev N. ${ }^{1}$, P. Bochev ${ }^{2}$, Sk. Kalevski ${ }^{1}$, A. Klisarova ${ }^{2}$ \\ ${ }^{1}$ Department of Neurosurgery, ${ }^{2}$ Department of Nuclear Medicine, \\ Medical University - Varna, Bulgaria
}

Reviewed by: Assoc. Prof. G. Kiuchukov

\begin{abstract}
According the published data concerning the problem Brain Metastases(BMs), the number of the patients with malignant diseases, also patients in the final IV stage (TNM) constantly and steadily increases, despite the tremendous and continuous advancement of the modern medicine. So, the adequate treatment of this group of population is an actual problem. At present the CT-Scan and MRI are standard for diagnostication of BMs, but they have little or no prognostic value for the effect that should be anticipated from the application of one or another therapeutic approach (surgical treatment, radiotherapy, chemotherapy).Single-Photon Emission Computed Tomography (SPECT) is a method of choice for evaluation of brain perfusion. Now it is well known that the brain perfusion is tightly coupled with the brain metabolism, respectfully with the brain function. With the present study we aim to evaluate with SPECT the brain perfusion of patients with BMs, also to reveal correlations with the extent of brain edema and with the quality of life of these patients. Demonstration of influence from the different therapeutic strategies to the brain perfusion could be used for optimization of the treatment of these patients.
\end{abstract}

Keywords: brain, metastases, edema, perfusion, SPECT

\section{INTRODUCTION}

According the published data concerning the problem Brain Metastases (BMs), the number of the patients with malignant diseases, also patients in the final IV stage (TNM) and respectively patients with BMs constantly and steadily increases, despite the tremendous and continuous advancement of the modern medicine. Early diagnostics and treatment of BMs with application of modern high technology diagnostic and treatment tools results in increased detection and successful treatment. The prolonged survival of the primary tumors also contributes for the increase of the patients with BMs. According to the literature about $20-40 \%$ of the patients with neoplastic diseases develop BMs and presently comprise about $0,15 \%$ of the population of the earth.

It is well known that presence of BMs indicate that patients are in the final IV stage (TNM) with the respective prognosis for the life expectancy that is estimated to be less than a year. Irrespective of the statistically bad prognosis, a correctly chosen therapeutic approach adds to the improvement of the quality of life mainly through the reduction of the intracranial hypertension, neurologic deficiency and pain.

Address for correspondence:

N. Peev, Dept. of Neurosurgery, Medical University of Varna,

55 Marin Drinov str., BG-9002, Varna

e-mail: nikolay.a.peev@gmail.com
Therefore the problems that relate to the optimal surgical approach are of significant importance and the progress of the surgical treatment of BMs is a question of present interest. Hence the different diagnostic and therapeutic methods are an issue for serious discussions.

Currently the role of MRI as a top diagnostic tool that is superior to CT scan for visualization of BMs is not debatable. $(4,5,6)$.

However MRI as CT Scan has no or little prognostic significance for the expected effect from the application of different therapeutic modalities (surgical treatment, radiotherapy, chemotherapy) concerning BMs.

Single photon emission computed tomography is a method of choice for evaluation of cerebral perfusion $(7,8,9,10)$.

It is well known that the cerebral perfusion is tightly coupled with the cerebral metabolism, respectively with the brain function $(11,12)$. Having information for the cerebral blood flow and volume, one could elaborate on the brain function of the respected patient, also to evaluate the potential effect of a particular therapeutic approach

Demonstrating a relationship between the brain perfusion and the effect of the different therapeutic approaches could be used for the optimization of the applied treatment strategies.

With the present study we aim to evaluate the cerebral perfusion of the patients with BMs and to demonstrate correlations with the extent of the brain edema, also with the quality of life of the patients 


\section{MATERIAL AND METHODS}

With SPECT is evaluated the cerebral perfusion of 14 patients with BMs treated in the Clinic of Neurosurgery, "St. Anna" District Hospital.

For the purpose of the perfusion study $740 \mathrm{MBq}$ $99 \mathrm{mTcHMPAO}$ was injected intravenously with imaging starting after $20 \mathrm{~min}$ of application. Study was carried out on single headed gamma camera using LEHR collimator, $128 X 128$ matrix, 120 projections, $20 \mathrm{sec}$ per projection, Reconstructed with Filtered back projection in coronal, transverse and sagital plain with Chang's attenuation correction (0.11).

Table 1. Calculated indexes of perfusion

\begin{tabular}{||c|c|c|c|c|c||}
\hline \hline № & $\begin{array}{c}\text { Tumor/ } \\
\text { Peritumo- } \\
\text { ral } \\
\text { area(X) }\end{array}$ & $\begin{array}{c}\text { Tumor } \\
\text { Contrala- } \\
\text { teral area } \\
\text { (Y) }\end{array}$ & $\begin{array}{c}\text { Peritumo- } \\
\text { ral/Contra } \\
\text { lateral } \\
\text { area (Y/X) }\end{array}$ & $\begin{array}{c}\text { Perifocal } \\
\text { edema } \\
\mathbf{1 - 3}\end{array}$ & $\begin{array}{c}\text { Spitzer- } \\
\text { QOL }\end{array}$ \\
\hline 1 & 0,93 & 0,77 & 0.828 & 2 & 7 \\
\hline 2 & 0,87 & 0,80 & 0.920 & 1 & 9 \\
\hline 3 & 0,95 & 0,87 & 0.916 & 1 & 8 \\
\hline 4 & 0,85 & 0,73 & 0.859 & 2 & 8 \\
\hline 5 & 0,85 & 0,80 & 0.941 & 1 & 9 \\
\hline 6 & 0,80 & 0,63 & 0.788 & 2 & 7 \\
\hline 7 & 0,71 & 0,70 & 0.986 & 1 & 9 \\
\hline 8 & 0,93 & 0,98 & 1.054 & $3+$ & 7 \\
\hline 9 & 0,73 & 0,67 & 0.918 & 1 & 9 \\
\hline 10 & 0,85 & 0,87 & 1.024 & $3+$ & 7 \\
\hline 11 & 0,87 & 0,86 & 0.989 & 1 & 9 \\
\hline 12 & 0,59 & 0,54 & 0.915 & 1 & 9 \\
\hline 13 & 0,87 & 0,88 & 1.011 & $3+$ & 7 \\
\hline 14 & 0,63 & 0,62 & 0,984 & 2 & 7 \\
\hline
\end{tabular}

Indexes of perfusion are calculated as follows:

- Tumor / Peritumoral area

- Tumor / Corresponding contra lateral zone

- Peritumoral area / Corresponding contralateral zone

The calculated indexes are presented in Table 1.

The calculated indexes for every patient are juxtaposed with the extent of the brain edema $(1+, 2+$, and $3+$ respectively) and with Spitzer Quality of Life (QOL) Score.

The patients are divided on tree groups according to the extent of the brain edema and according to the Spitzer $Q O L$ Score (Table 2).

The brain edema is denoted with $1+$ when there is a perifocal brain edema that is localized in one brain lobe; $2+$ when there is a brain edema with moderate extent, involv- ing 2 brain lobes; $3+$ when the brain edema is extended over 3 and more brain lobes.

Table 2. Patients groups respecting the extent of the brain edema/ Spitzer QOL score

\begin{tabular}{||c|c|c|c|c|c||}
\hline \hline \multicolumn{3}{||c|}{ Brain Edema } & \multicolumn{3}{c||}{ Spitzer QOL Score } \\
\hline $\begin{array}{c}\text { Group 1 1+ } \\
\text { - Group 2 } \\
\text { - 2+ }\end{array}$ & $\begin{array}{c}\text { Group 3 } \\
\text { - 3+ }\end{array}$ & $\begin{array}{c}\text { Group 1 } \\
\text { - QOL 7 }\end{array}$ & $\begin{array}{c}\text { Group 2 } \\
\text { - QOL 8 }\end{array}$ & $\begin{array}{c}\text { Group 3 } \\
\text { - QOL 9 }\end{array}$ \\
\hline 0,92 & 0,828 & 1,054 & 0,828 & 0,916 & 0,92 \\
\hline 0,916 & 0,859 & 1,024 & 0,788 & 0,859 & 0,941 \\
\hline 0,941 & 0,788 & 1,011 & 1,054 & & 0,986 \\
\hline 0,986 & 0,884 & & 1,024 & & 0,918 \\
\hline 0,918 & & & 0,884 & & 0,989 \\
\hline 0,989 & & & 1,011 & & 0,915 \\
\hline 0,915 & & & & & \\
\hline
\end{tabular}

Considering Spitzer QOL Score patients are divided on tree groups with score 7, 8 and 9 respectively.

\section{RESULTS}

In $100 \%$ of the cases that were studied we found hypoperfusion in the area of the tumor tissue, also in the adjacent peritumoral brain parenchyma.

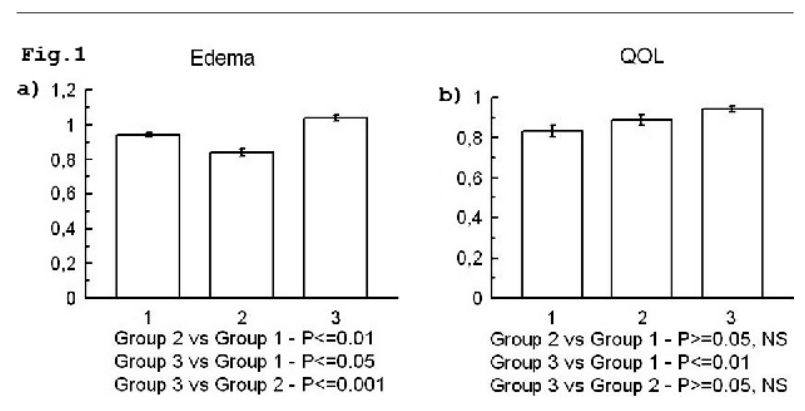

Fig.1. The figure presents a statistical analysis of the perfusion indexes. There is a statistically significant difference $(P<0.05$, one-way ANOVA) when juxtaposing the calculated perfusion indexes of the patient from the tree different groups that are set on the base of the different extent of the brain edema - group $1(1+)$, group $2(2+)$ and group $3(3+)$ respectively. When juxtaposing the calculated perfusion indexes of the patient from the tree different groups that are set on the base of the differences of QOL score, there is a statistically significant difference $(P<0.05$, one-way ANOVA) among the patients from group 1(QOL 7) and group 3(QOL 9) When compare group 1(QOL7) with group 2(QOL8) and group 2(QOL8) with group3(QOL9) the differences are non-significant(NS) - $P>0.05$ (one-way ANOVA).

There is a statistically significant difference $(\mathrm{P}<0.05$, one-way ANOVA) when juxtaposing the calculated perfusion indexes 
of the patient from the tree different groups that are set on the base of the different extent of the brain edema - group 1(1+), group 2(2+) and group 3(3+) respectively (Fig. 1.)

When juxtaposing the calculated perfusion indexes of the patient from the tree different groups that are set on the base of the differences of QOL score, there is a statistically significant difference $(\mathrm{P}<0.05$, one-way ANOVA) among the patients from group 1(QOL 7) and group 3 (QOL 9). When compare group 1(QOL7) with group 2(QOL8) and group 2(QOL8) with group3(QOL9) the differences are non-significant(NS) $-\mathrm{P}>0.05$ (one-way ANOVA). (Fig. 1) In 4 of the studied cases we performed also postoperative (30 days after the resection of the BMs) follow up with SPECT. In these cases we found an increase of the cerebral perfusion in the zone of the resected brain metastasis (Fig.2).

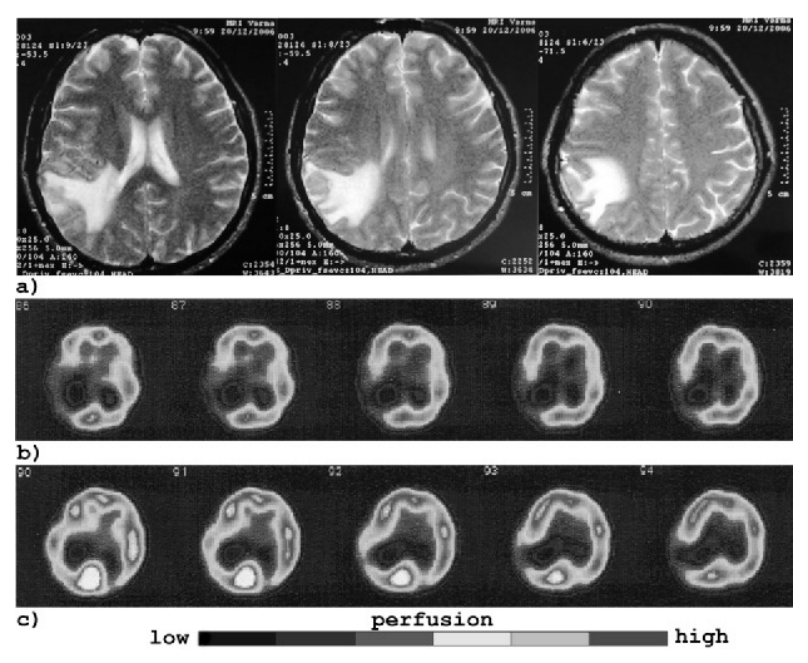

Fig. 2. The figure presents: (a) T2 MRI of patient with brain metastasis in the right parietal brain lobe and perifocal brain edema spead to the adjacent to the tumor brain parenchyma; (b) Preoperative SPECT Scan with $99 \mathrm{mTCHMPAO}$ that demonstrates perfusion defect (decreased to absent perfusion) in the area of the brain metastasis and the perifocal brain edema; (c) Post operative 99mTcHMPAO SPECT Scan that demonstrates decrease in the perfusion defect - the area with absent and decreased perfusion is smaller if compare with the preoperative SPECT Scan.

\section{DISCUSSION}

Based on the aforementioned investigations could be made an important deductions considering the significance of the different therapeutic approaches, including the surgical treatment, also the application and usefulness of the SPECT with patients diagnosed with BMs.

The statistical data demonstrates that the number of the patients with neoplastic diseases is constantly growing. With the progress of the modern medicine, the longevity of the patients with malignancies is also increasing $(13,14)$. All this inevitably results in increase of the patients with metastases, and in particular patients with BMs (15).
However despite the tremendous and constant efforts towards the increase the longevity of the patients with neoplastic diseases in the last decades, it is not much that has been achieved. In that respect the different diagnostic and therapeutic approach of BMs patients is an issue for serious discussions. One of the important questions analyzed is the surgical treatment.

A number of investigations show that the patients with excised BMs live longer if compare with those treated conservatively. Unfortunately the prolongation of the life is within months. Based on this some authors claim that surgical treatment for BMs should be abandoned and the conservative approaches primarily, like Radiotherapy and Chemotherapy should be practiced.

Thus more and more clinicians support the statement that the surgical treatment should be discussed as an option mainly for the patients with single and surgically accessible BMs, with significant mass effect, obstructive hydrocephalus and missing or controlled systemic disease. In terms of the benefits expected (improved QOL, increased life expectancy) it is considered that this group is the most appropriate for treatment with more aggressive therapeutic regiments that include surgery. Applying the aforementioned criteria, most of the neurosurgical clinics reports that only about $10-20 \%$ of the patients are selected as appropriate candidates for surgery $(16,17,18,19,21,22)$.

However there is still no consensus for the place of the surgery in the treatment of the BMs patients. Another group of clinicians support the opinion that the surgical treatment could be beneficial for the majority of the patients with BMs and treatment regiments that include surgery should not be considered as an option only for the patients that reflect the aforementioned conditions. Some authors report results suggesting that the indications for surgical excision of BMs should be widened and even the patients with disseminated neoplastic disease could have benefit from BMs excision. Especially if the QOL of these patients is taken under consideration, they could be good candidates for surgical treatment. Now it is believed that the survival is a parameter that should be evaluated together with not less important QOL of the patient. In that respect, the surgical removal of BMs usually causes relief of the intracranial hypertension symptoms, reduction of brain edema, reduction of the focal neurologic deficit, epileptic seizures, also steroid dose reduction, etc. $(20,23,24)$.

Now it is well known that the cerebral perfusion is directly related to the brain function (25). The results from our study show that the BMs reduce the cerebral perfusion in the adjacent to BMs parenchyma. Furthermore the analysis of our results suggest that the perfusion reduction correlates on the one hand with the extent of the adjacent brain edema, also with the QOL of the patient on the other. Hence there is indirect relation between edema and QOL of the patients with BMs through the cerebral perfusion.

Regarding the aforesaid, the surgical treatment of BMs could be considered as a method for fast and definitive relief of the cerebral edema and intracranial hypertension, consequently method for improvement of the brain functioning, hence QOL of the patients. 


\section{CONCLUSION}

- In $100 \%$ of the investigated patients the adjacent to BMs brain parenchyma is hypoperfused.

- In $100 \%$ of the investigated patients the zone of the BMs is hypoperfused.

- The extent of the hypoperfusion is related to the extent of the brain edema in the adjacent to BMs brain parenchyma

- The perfusion abnormalities that reflect the impairment of the brain functioning could be objectified with appropriate QOL scoring systems.

- Surgical removal of BMs causes improvement of of the cerebral perfusion, consequently improvement of the brain function.

- Improvement of the cerebral perfusion, hence brain function and QOL of the patients with BMs could be achieved through surgical removal of the BMs. Therefore the indications for surgical removal of the BMs could be extended, considering not only the parameter survival, but also the QOL of the patients.

\section{REFFERENCES}

1. Massot-Punyet R, Almajano J (2000). Cerebral metastases. Rev Neurol 31(12): 1242-1247.

2. Bartumeus F, Clavel P (2000). Surgical treatment of brain metastases. Rev Neurol. 31(12): 1247-1249.

3. Lohr F, Pirzkall A, Hof H, Fleckenstein K, Debus J (2001). Adjuvant treatment of brain metastases. Semin Surg Oncol. 20(1): 50-56.

4. Sze G, et al (1990). Detection of brain metastases: Comparison of contrast-enchanced MR with unenchanced MR and enchanced CT. Am J Neuroradiol 11: 785-791.

5. Sze G, Johnson C, Kawamura Y, Goldberg SN, Lange R, Friedland RJ, Wolf RJ (1998). Comparison of single- and triple-dose contrast material in the MR screening of brain metastases. Am J Neuroradiol 19: 821-828.

6. Davis PC, Hudgins PA, Peterman SB (1991). Diagnosis of cerebral metastases: Double dose delayed CT vs. contrast enchanced MRI. Am J Neuroradiol 12:293-300.

7. Syed GS (1992). Quantification of regional cerebral blood (rCBF) using Tc-99m HM-PAO and SPECT: choice of the reference region. Nucl Med Comm. 13:811-816.

8. Babich JW, Keeling F, Flower MA, Repetto L, Whitton A, Fieding S, et al (1988). Initial experience with Tc-99m-HM-PAO in the stud of brain tumors. Eur Nucl Med 14: 39-44.

9. Lindegaad MW, Skretting A, Hager B, Watne K, Lindegaard KF (1986). Cerebral and cerebellar uptake of Tc-99m(d,1)-hexamethyl-propyleneamine oxime (HM-PAO) in patients with brain tumor studied by single photon emission computerized tomography. Eur J Nucl Med 12: 417-420.

10. Wintermark M, Sesay M, Barbier E, Borbйly K, Dillon WP, Eastwood JD, Glenn TC,. Grandin CB, Pedraza S, Soustiel J-F, Nariai T, Zaharchuk G, Caillй J-M, Dousset V, Yonas H (2005). Comparative Overview of Brain Perfusion Imaging Techniques. Stroke 36:e83-e99.

11. Coles JP (2006). Imaging of cerebral blood flow and metabolism. Curr Opin Anaesthesiol 19(5):473-80.

12. Warwick JM (2004). Imaging of brain function using SPECT. Metab Brain Dis 19:113-123.

13. WHO. Fact sheet $\mathrm{N}^{\circ} 297$ February 2006. http://www.boveran.biz/pdf/WHO\%20Cancer\%20fac $\mathrm{t} \% 20$ sheet.pdf

14. WHO. World health statistics 2007. http://www.who.int/whosis/whostat2007_10highlights .pdf

15. Massot-Punyet R and Almajano J (2000). Cerebral metastases. Rev Neurol 31(12):1242-1247.

16. Lang FF, Chang EL, Abi-Said D, Wildrick DM, Sawaya R (2005). Metastatic Brain Tumors. In: Winn RH (ed) Youmans Neurological Surgery(5ed).Elsevier, New York, pp.1077-1097.

17. Lohr F, Pirzkall A, Hof H, Fleckenstein K, Debus J (2001). Adjuvant treatment of brain metastases. Semin Surg Oncol 20(1):50-56.

18. Posner JB and Chernik NL (1978). Intracranial metastases from systemic cancer. Adv Neurol 19:579-592.

19. Vecht CJ (1998). Clinical management of brain metastasis. J Neurol 245:127-131

20. Sheehan J, Niranjan A, Flickinger J, Kondziolka K, Lunsford D (2004). The expanding role of neurosurgeons in the management of brain metastases. Surg Neurol 62:32-41

21. Mintz AH, Kestle J, Rathbone MP, Gaspar L, Hugenholtz H, Fisher B, Duncan G, Skingley P, Foster G, Levine M (1996) A randomized trial to assess the efficacy of surgery in addition to radiotherapy in patients with a single cerebral metastasis. Cancer 78:1470-1476.

22. Patchell R A, Tibbs P A, Walsh JW, Dempsey RJ, Maruyama Y, Kryscio Markesbery WR, Macdonald JS, Young B (1990) A randomized trial of surgery in the treatment of single metastases to the brain. N Engl J Med 322:494-500.

23. Rajesh K. Bindal, Raymond Sawaya (1993). Surgical treatment of multiple brain metastases; $J$ Neurosurg 79:210 - 216.

24. Pollock B, Brown PD, Foote RL, Stafford SL, Schomberg PJ (2003) Properly selected patients with multiple brain metastases may benefit from aggressive treatment of their intracranial disease. $J$ Neurooncol 61:73-80.

25. Shiraishi H, Chang CC, Kanno H, Yamamoto I (2003). The relationship between cerebral blood flow and cognitive function in patients with brain insult of various etiology. J Clin Neurosci

11(2):138-41. 